\title{
Aspectos florísticos e econômicos das pteridófitas de um afloramento rochoso do Estado do Rio de Janeiro, Brasil ${ }^{1}$
}

\author{
Marcelo Guerra Santos ${ }^{2,4}$ e Lana da Silva Sylvestre ${ }^{3}$
}

Recebido em 9/02/2004. Aceito em 16/07/2005.

\begin{abstract}
RESUMO - (Aspectos florísticos e econômicos das pteridófitas de um afloramento rochoso do Estado do Rio de Janeiro, Brasil). O presente trabalho apresenta o levantamento das pteridófitas ocorrentes na Pedra de Itacoatiara, afloramento rochoso localizado no Parque Estadual da Serra da Tiririca, no litoral do Município de Niterói, Estado do Rio de Janeiro, Brasil. Foram registradas 24 espécies pertencentes a 15 gêneros e nove famílias. As famílias encontradas foram Aspleniaceae, Blechnaceae, Dennstaedtiaceae, Lycopodiaceae, Polypodiaceae, Pteridaceae, Schizaeaceae, Selaginellaceae e Thelypteridaceae. Dessas, a mais representativa foi Pteridaceae com oito espécies distribuídas em cinco gêneros (Adiantum, Adiantopsis, Doryopteris, Hemionitis e Pityrogramma). Os gêneros com maior número de espécies foram Anemia (quatro espécies) e Selaginella (três). É apresentada uma chave de identificação e, para cada espécie, são fornecidas informações sobre o padrão de distribuição geográfica, utilidades atribuídas e observações ecológicas. Das 24 espécies encontradas, 13 são úteis ao homem (medicinal, comestível, ornamental, ritualística e cosmética) e duas são tóxicas.
\end{abstract}

Palavras-chave : Mata atlântica, plantas medicinais, vegetação litorânea, monilophyta, licophyta

\begin{abstract}
Floristics and economics aspects of the pteridophytes of rocky outcrop from Rio de Janeiro State, Brazil). This work presents the inventory of the pteridophytes from Pedra de Itacoatiara. This area is formed by rock outcrop and belongs to Parque Estadual da Serra da Tiririca, on the coast of Niterói, Rio de Janeiro State, Brazil. Twenty four species were registered, belonging to 15 genera and nine families. The families Aspleniaceae, Blechnaceae, Dennstaedtiaceae, Lycopodiaceae, Polypodiaceae, Pteridaceae, Schizaeaceae, Selaginellaceae and Thelypteridaceae were registered in this area. The richest family was Pteridaceae with eight species and five genera (Adiantum, Adiantopsis, Doryopteris, Hemionitis and Pityrogramma). The richest genera were Anemia (four species) and Selaginella (three). A key is provided for species identification. Geographic distribution and attributed usages are also given, as well as comments about ecological features. Thirteen species are useful to men (medicinal, feeding, ornamental, folklore rituals and cosmetic) and two are toxic.
\end{abstract}

Key words: Atlantic rain forest, medicinal plants, coastal vegetation, monilophyte, licophyte

\section{Introdução}

Os afloramentos rochosos abrigam um ecossistema de estrutura frágil, com hábitat singular e muitas espécies endêmicas (Meirelles et al. 1999). Possui uma flora que muitas vezes difere marcadamente da vegetação que lhe faz limite (Porembski \& Barthlott 2000; Porembski 2002). Essas formações são denominadas "inselbergs" (do alemão, insel = ilha; berg $=$ montanha) $($ Porembski 2002). As comunidades vegetais dos afloramentos rochosos recebem pouca atenção dos cientistas e ambientalistas (Meirelles et al. 1999), sendo poucos os trabalhos que enfocam esta vegetação.
Apesar da existência de alguns trabalhos realizados em locais de constituição rochosa no estado do Rio de Janeiro, são poucas as referências de pteridófitas. Oliveira et al. (1975), estudando as encostas rochosas nos maciços da Tijuca e Pedra Branca, citam apenas duas espécies de pteridófitas: Doryopteris sp. e Selaginella sp.; Carauta \& Oliveira (1982) listam para as encostas do Pão de Açúcar quatro espécies de pteridófitas: Anemia phyllitidis (L.) Sw., Blechnum unilaterale $\mathrm{Sw}$. (=Blechnum polypodioides Raddi), Doryopteris sp. e Gleichenia bifida (Willd.) Spreng. [=Sticherus bifidus (Willd.) Ching]; Meirelles et al. (1999) registram seis espécies de pteridófitas pertencentes a cinco gêneros e quatro famílias,

\footnotetext{
1 Monografia de Bacharelado do primeiro Autor

2 Universidade do Estado do Rio de Janeiro, Departamento de Ciências, Faculdade de Formação de Professores, Rua Dr. Francisco Portela 794, CEP 24435-000, São Gonçalo, RJ, Brasil

3 Universidade Federal Rural do Rio de Janeiro, Departamento de Botânica, BR 465 km 7, CEP 23890-000, Seropédica, RJ, Brasil

4 Autor para correspondência: mguerras@bol.com.br
} 
realizando coletas em oito áreas no estado do Rio de Janeiro. A Pedra de Itacoatiara foi incluída neste trabalho, sendo registradas as seguintes espécies: Doryopteris collina (Raddi) J. Sm., Polypodium loriceum L. e Selaginella sellowii Hieron.

O presente trabalho teve como objetivos caracterizar as pteridófitas existentes na Pedra de Itacoatiara, relatar como são utilizadas economicamente e apontar alguns aspectos ecológicos destas espécies. Pretendeu-se também, com este estudo, contribuir para o conhecimento da pteridoflora ocorrente nos afloramentos rochosos litorâneos do estado do Rio de Janeiro.

\section{Material e métodos}

Área de estudo - A Pedra de Itacoatiara, situada no município de Niterói-RJ entre as coordenadas geográficas de $22^{\circ} 58^{\prime} 33^{\prime}$ '- $22^{\circ} 59^{\prime} 00^{\prime}$ 'S e $43^{\circ} 01^{\prime} 33^{\prime \prime}$ $43^{\circ} 02^{\prime} 00^{\prime}$ 'W, pertence ao Parque Estadual da Serra da Tiririca. Trata-se de um afloramento rochoso de granito-gnaisse (Meirelles et al. 1999), limitado de um lado pela floresta ombrófila densa de encosta e, de outro, pelo mar. Com cerca de $200 \mathrm{~m}$ de altitude é constituído de vertentes com angulações variadas, onde o acúmulo de matéria orgânica e sedimentos, sobre a rocha nua, forma camadas de solo de espessuras variadas, propiciando a instalação da vegetação. Essas formações são conhecidas como ilhas de solo (Meirelles et al. 1999). No cume e no sopé, ocorrem indivíduos de porte arbóreo que formam pequenas matas. São encontradas plantas terrestres, rupícolas, epífitas e hemiepífitas. As maiores limitações ao estabelecimento da vegetação são o déficit hídrico ao qual esta é submetida, as altas temperaturas, que podem chegar a $50^{\circ} \mathrm{C}$ na superfície da rocha, a reduzida disponibilidade de substrato para as espécies terrestres e a influência da salinidade (Pontes 1987; Meirelles et al. 1999; Porembski \& Barthlott 2000).

Coleta e tratamento do material botânico - O presente trabalho foi realizado a partir da análise do material botânico coletado (37 espécimes) pelo primeiro autor. Os indivíduos foram coletados e herborizados seguindose Silva (1984) e Windisch (1992). Todas as exsicatas foram depositadas no Herbário do Instituto de Pesquisas do Jardim Botânico do Rio de Janeiro (RB) e no Herbário da Faculdade de Formação de Professores da Universidade do Estado do Rio de Janeiro (RFFP, não indexado).

O sistema de classificação adotado foi o de Kramer \& Green (1990), com modificações para o tratamento da família Polypodiaceae, reconhecendose o gênero Microgramma sensu Tryon \& Tryon (1982). A abreviação dos nomes dos autores dos táxons está de acordo com Pichi Sermolli (1996). Os padrões de distribuição geográfica foram obtidos com base no levantamento das coleções dos seguintes herbários: Instituto de Pesquisas do Jardim Botânico do Rio de Janeiro (RB) e Museu Nacional - UFRJ (R) e nas informações contidas nas seguintes referências bibliográficas: Tryon (1941; 1942; 1962), Mickel (1962), Brade (1965; 1972), Murillo (1968), Sehnem (1968; 1970; 1972; 1974; 1979), Braga (1976), Alston et al. (1981), Øllgaard \& Windisch (1987), Mickel \& Beitel (1988), Tryon \& Stolze (1989a; 1989b; 1993), Hensen (1990), Smith (1992), Hirai \& Prado (2000), Sylvestre \& Windisch (2002) e Salino \& Semir (2002). A caracterização das espécies quanto às formas de vida baseou-se na chave proposta por Mueller-Dombois \& Ellenberg (1974), que está fundamentada no sistema de Raunkiaer. Os nomes populares e utilidades atribuídas às espécies foram obtidas nas seguintes referências bibliográficas: Lima (1940), Mas-Guindal (1941), Penna (1946), Stellfeld (1951), Cruz (1965), Braga (1976), May (1978), Corrêa (1984), Hertwig (1986), Zurlo \& Brandão (1989), Roriz (1992), Barros \& Andrade (1997) e Santos \& Sylvestre (2000). Esses itens não foram incluídos no tratamento das espécies que não possuíam informações sobre os nomes populares e/ou usos atribuídos.

\section{Resultados e discussão}

Chave para as espécies de Pteridófitas na Pedra de Itacoatiara, RJ

1. Microfilos; um esporângio na base de cada esporofilo, formando estróbilos ou não

2. Rizóforos ausentes

4. Lycopodiella cernua

2. Rizóforos presentes

3. Microfilos monomorfos e dispostos espiraladamente; esporângios em esporofilos ao longo da porção mediana e distal dos ramos 21. Selaginella sellowii 
3. Microfilos dimorfos e dispostos dorsiventralmente; esporângios em esporofilos formando estróbilos terminais

4. Microfilos axilares com duas aurículas na base; microfilos laterais com base assimétrica e lado acroscópico auriculado 22. Selaginella sulcata

4. Microfilos axilares e laterais com base obtusa, não auriculada ..............20. Selaginella muscosa

1. Megafilos; alguns a muitos esporângios na face abaxial ou na margem das folhas ou em pinas basais modificadas

5. Esporângios em um par de pinas basais modificadas (na forma de espiga)

6. Folhas pinadas

7. Caule horizontal; pinas oblongas, margem incisa, base cuneada 17. Anemia hirsuta

7. Caule vertical; pinas ovado-lanceoladas, margem inteira a crenada, base assimétrica com lado acroscópico auriculado 16. Anemia collina

6. Folhas pinado-pinatissectas a bipinadas

8. Folhas pinado-pinatissectas; caule ascendente

19. Anemia villosa

8. Folhas bipinadas; caule horizontal subterrâneo 18. Anemia tomentosa var. anthriscifolia

5. Esporângios em soros na superfície abaxial ou na margem das folhas, ou dispostos sobre toda a face abaxial

9. Esporângios dispostos sobre a superfície abaxial das folhas; face abaxial de cor alva ou amarelada

15. Pityrogramma calomelanos var. calomelanos

9. Esporângios em soros na superfície abaxial ou na margem das folhas; face abaxial de coloração diferente

10. Soros na superfície abaxial das folhas

11. Soros lineares

12. Lâmina foliar pilosa; indúsio ausente

14. Hemionitis tomentosa

12. Lâmina foliar glabra; indúsio presente

13. Folhas inteiras; nervuras anastomosadas; soros oblíquos em relação à costa e dipostos sobre as nervuras secundárias 1. Antigramma plantaginea

13. Folhas pinadas; nervuras livres; um soro de cada lado da costa, paralelos a esta e dipostos sobre uma comissura vascular

2. Blechnum serrulatum

11. Soros arredondados

14. Folhas inteiras, pinatissectas ou pinadas

15. Folhas inteiras, dimorfas

5. Microgramma vacciniifolia

15. Folhas pinatissectas ou pinadas, monomorfas

16. Soros formando uma série paralela à costa; folhas pinatissectas; segmentos oblongas, base decurrente, ápice obtuso.... 6. Polypodium catharinae

16. Soros formando duas ou três séries paralelas à costa; folhas pinadas; pinas lanceoladas, base assimétrica, ápice agudo

7. Polypodium triseriale

14. Folhas pinado-pinatífidas ou bipinado-pinatissectas

17. Folhas pinado-pinatífidas

24. Thelypteris dentata

17. Folhas bipinado-pinatissectas 23. Macrothelypteris torresiana

10. Soros marginais

18. Folhas inteiras

19. Pecíolo cilíndrico, negro; nervuras anastomosadas 13. Doryopteris varians

19. Pecíolo sulcado ou achatado, castanho-escuro; nervuras livres ou anastomosadas 20. Pecíolo sulcado adaxialmente; nervuras livres 12. Doryopteris concolor

20. Pecíolo achatado adaxialmente; nervuras anastomosadas 11. Doryopteris collina

18. Folhas bipinadas a quadripinado-pinatissectas

21. Folhas quadripinado-pinatissectas, com mais de $1 \mathrm{~m}$ de comprimento; segmentos fortemente coriáceos e quebradiços 3. Pteridium aquilinum var. arachnoideum

21. Folhas bipinadas ou tripinadas, com menos de $1 \mathrm{~m}$ de comprimento; segmentos membranáceos ou subcoriáceos 
22. Cada soro na terminação de uma única nervura; lâminas radiadas

8. Adiantopsis radiata

22. Cada soro na terminação de mais de uma nervura; lâminas pinadamente ramificadas

23. Folhas bipinadas; segmentos oblongos, base assimétrica, ápice obtuso

10. Adiantum serratodentatum

23. Folhas tripinadas na base; segmentos flabeliformes, base cuneada, ápice inciso-crenado

9. Adiantum raddianum

Aspleniaceae

\section{Antigramma plantaginea (Schrad.) C.Presl}

Hemicriptófita rosulada endêmica do Brasil, ocorrendo nos estados do Espírito Santo e Rio de Janeiro. Facilmente reconhecida pelas suas folhas lanceolado-ovadas, nervuras anastomosadas e soros lineares indusiados sobre as nervuras secundárias. $\mathrm{Na}$ área de estudo, ocorre apenas no interior da mata existente no sopé da Pedra, na vertente sudeste, em solos com espessa camada de húmus.

Material examinado: BRASIL. Rio de Janeiro: Niterói, 2/I/1994, Guerra Santos 31 (RB); 16/IV/1995, Guerra Santos et al. 68 (RB).

\section{Blechnaceae}

\section{Blechnum serrulatum Rich.}

Geófita rizomatosa com distribuição pantropical. Distinta por suas pinas serreadas e os soros lineares com indúsios localizados um de cada lado da costa. Encontra-se crescendo nas ilhas de solo junto com Pteridium aquilinum var. arachnoideum e sapê (Imperata brasiliensis Trin. - Poaceae). O chá é utilizado para combater edemas (Barros \& Andrade 1997).

Material examinado: BRASIL. Rio de Janeiro: Niterói, 20/III/1994, Guerra Santos et al. 52 (RB); 27/VIII/1995, Guerra Santos 385 (RB).

\section{Dennstaedtiaceae}

\section{Pteridium aquilinum (L.) Kuhn var. arachnoideum (Kaulf.) Brade}

Geófita rizomatosa com distribuição neotropical. Espécie facilmente reconhecida na Pedra de Itacoatiara pela divisão de sua folha (quadripinadopinatissecta), segmentos fortemente coriáceos e quebradiços e soros marginais. $\mathrm{Na}$ área de estudo é encontrada em clareiras abertas na mata existente no sopé do afloramento (vertente sudeste) e em ilhas de solo próximas a esta mata. Encontra-se crescendo junto com Blechnum serrulatum e Pityrogramma calomelanos var. calomelanos. Conhecida popularmente como feio, feto-águia, pluma-grande, samambaia-das-taperas, samambaia-dura, samambaia-verdadeira, samambaia-das-roças ou samambaia-das-queimadas (Corrêa 1984; Zurlo \& Brandão 1989). São atribuídas a esta espécie usos comestível e medicinal. Os báculos desta samambaia, que o povo chama de "munheca", são comercializados em certas cidades do interior de Minas Gerais (Corrêa 1984). Para serem consumidos, os báculos devem ser picados e aferventados, pelo menos cinco vezes, até perder completamente o gosto amargo. Esse amargo, segundo Zurlo \& Brandão (1989), equivale aos princípios tóxicos da samambaia. Santos et al. (1987) demonstraram que a ingestão de báculos de P. aquilinum induziu a formação de tumores no trato gastrointestinal de ratos. Estudos em outras variedades desta espécie também demonstraram ação carcinogênica e mutagênica, fato este que fez alguns autores sugerirem que ela seja retirada das listas de plantas comestíveis (Hodge apud May 1978). Planta invasora (Lima 1940), considerada nociva e tóxica para os animais domésticos, especialmente cavalos, quando ingerida cumulativamente (Hoehne 1939; Corrêa 1984; Barros \& Andrade 1997). Santos et al. (2005) indicam que esta variedade possui atividade cianogênica em seus báculos. Os glicosídeos cianogênicos são substâncias de defesa encontradas em alguns vegetais, capazes de liberar ácido cianídrico através de reações de hidrólise (Harborne 1984). A infusão das folhas é indicada como antireumática e os báculos servem para combater a expectoração sanguinolenta e a rouquidão. A decocção dos rizomas é utilizada para acalmar a tosse dos tuberculosos em grau adiantado e é também sudorífera (Lima 1940; Corrêa 1984). Santos \& Sylvestre (2000) comentam que a espécie é utilizada para forrar caixotes de hortaliças e Hertwig (1986) que as folhas possuem ação inseticida e acaricida. 
Material examinado: BRASIL. Rio de Janeiro: Niterói, 2/I/1994, Guerra Santos et al. 38 (RB); 27/VIII/1995, Guerra Santos 393 (RB).

Lycopodiaceae

\section{Lycopodiella cernua (L.) Pic. Serm.}

Hemicriptófita reptante de distribuição pantropical. Na Pedra de Itacoatiara é encontrada nas ilhas de solo e reconhecida pelo caule vertical e intensamente ramificado, com microfilos filiformes e estróbilos terminais recurvados. Segundo Øllgaard \& Windisch (1987), é uma espécie pioneira bastante comum em áreas perturbadas ao longo de caminhos e clareiras em florestas. Conhecida popularmente como pé-degalinha, pinheirinho ou palma-de-São-João, é utilizada como medicinal com as seguintes indicações: diurética, antidiarréica, adstringente, antiinflamatória e antireumática (Barros \& Andrade 1997).

Material examinado: BRASIL. Rio de Janeiro: Niterói, 2/IV/1999, Guerra Santos et al. 1112 (RB).

Polypodiaceae

\section{Microgramma vacciniifolia (Langsd. \& Fisch.)} Copel.

Epífita reptante e/ou hemicriptófita reptante de distribuição neotropical. $\mathrm{Na}$ área de estudo pode ser encontrada como corticícola e/ou rupícola e é facilmente reconhecida por seu caule longo, intensamente revestido por escamas e folhas dimorfas (as estéreis são ovadas e as férteis lanceoladas). Conhecida popularmente como erva-silvina, ervasilveira, erva-tereza, erva-de-lagarto, cipó-cabeludo, cipó-peludo, estanca-sangue ou erva-da-mamãe-oxum (Sehnem 1970; Braga 1976; Corrêa 1984; Barros \& Andrade 1997; Santos \& Sylvestre 2000), é utilizada como ritualística, cosmética (Santos \& Sylvestre 2000) e medicinal. Indicada como poderoso adstringente; recomendada nas hemorragias, expectorações sanguinolentas de tuberculosos, diarréias, disenterias, hematúrias e derramamento de sangue pelo nariz (Corrêa 1984; Cruz 1965; Penna 1946; Braga 1976). Utilizada também para o tratamento de cólicas intestinais e hidropisia (Barros \& Andrade 1997). Faz parte da composição química de um xarope comercializado em farmácias, indicado para o tratamento de doenças do aparelho respiratório (Santos \& Sylvestre 2000). Santos et al. (2005) indicam que esta espécie possui atividade cianogênica.

Material examinado: BRASIL. Rio de Janeiro: Niterói, 7///1995, Guerra Santos et al. 67 (RB).

\section{Polypodium catharinae Langsd. \& Fisch.}

Hemicriptófita reptante de distribuição limitada à América do Sul. Na área de estudo é encontrada somente nas ilhas de solo e reconhecida pelos pecíolos articulados ao caule, as folhas pinatissectas e os soros arredondados formando uma fileira longitudinal paralela à nervura principal. Espécie utilizada como ornamental (Corrêa 1984). As pinas são flexionadas para o lado adaxial, o que provavelmente contribui para uma menor absorção da energia solar, minimizando o efeito da radiação excessiva (Larcher 2000). Nos períodos secos, as plantas perdem parcialmente as suas folhas. A eliminação total ou parcial das folhas e a presença de um rizoma com parênquima aqüífero constituem importantes adaptações para evitar a dessecação (Larcher 2000). Provavelmente a espécie citada por Meirelles (1999) como P. loriceum L. para a Pedra de Itacoatiara seja $P$. catharinae.

Material examinado: BRASIL. Rio de Janeiro: Niterói, 20/III/1994, Guerra Santos et al. 51 (RB); 3/XII/1994, Guerra Santos 62 (RB).

\section{Polypodium triseriale Sw.}

Hemicriptófita reptante de distribuição neotropical. Facilmente reconhecida na área de estudo por seu pecíolo articulado ao caule, folha pinada e soros arredondados formando duas ou três séries longitudinais paralelas à nervura principal. $\mathrm{Na}$ área de estudo foi encontrada apenas uma população no cume do afloramento. Ocorre nas margens das matas, sendo que em épocas desfavoráveis, como em períodos secos, é difícil encontrá-la, pois provavelmente perde suas folhas. Possuem caule espesso e com parênquima aquífero semelhante ao de Polypodium catharinae, possivelmente com igual função, ou seja, evitar a dessecação. Conhecida popularmente como samambaia-cumaru ou pluma-parasita (Corrêa 1984; Sehnem 1970; Braga 1976), é utilizada como ornamental (Corrêa 1984) e medicinal. Contém cumarina (Corrêa 1984), que possui efeitos alelopáticos e antibióticos (Larcher 2000). A infusão ou xarope das folhas é empregado como antitussígeno na medicina doméstica (Braga 1976).

Material examinado: BRASIL. Rio de Janeiro: Niterói, 7/I/1995, Guerra Santos et al. 66 (RB); 16/IV/1995, Guerra Santos et al. 70 (RB).

Pteridaceae

\section{Adiantopsis radiata (L.) Fée}

Hemicriptófita rosulada de distribuição neotropical. Espécie distinta na Pedra de Itacoatiara por suas 
lâminas radiadas ocorrendo somente no interior das matas. Conhecida pelos nomes populares de avenca estrelada ou feto estrelado (Braga 1976; Barros \& Andrade 1997), é utilizada como ornamental (Braga 1976; Roriz 1992) e medicinal. A infusão ou lambedor são usados como peitoral e antitussígena (Lima 1940; Mas-Guindal 1941; Barros \& Andrade 1997).

Material examinado: BRASIL. Rio de Janeiro: Niterói, 20/III/1994, Guerra Santos et al. 53 (RB).

\section{Adiantum raddianum C. Presl}

Hemicriptófita reptante de distribuição neotropical. A espécie é facilmente reconhecida na Pedra de Itacoatiara pelas folhas tripinadas e segmentos flabeliformes. Habita preferencialmente lugares sombreados e muito úmidos com água escorrendo pela rocha. Na área de estudo é encontrada apenas uma população na vertente sudeste. Conhecida pelos nomes populares de avenca-de-folha-miúda, avenca-brasileira ou capilária (Lima 1940; Stellfeld 1951; Corrêa 1984) é utilizada como ornamental (Corrêa 1984; Braga 1976; Stellfeld 1951) e medicinal. A espécie é indicada como peitoral, sudorífera, antitussígena, emenagoga, emoliente e tônica (Corrêa 1984; Lima 1940; Stellfeld 1951; Barros \& Andrade 1997).

Material examinado: BRASIL. Rio de Janeiro: Niterói, 2/I/1994, Guerra Santos et al. 34 (RB); 27/VIII/1995, Guerra Santos 389 (RB).

\section{Adiantum serratodentatum Willd.}

Geófita rizomatosa de distribuição neotropical. Facilmente distinta na área de estudo pelas suas folhas bipinadas e soros marginais descontínuos com a margem enrolada formando falsos indúsios. Foi encontrada apenas uma população nas ilhas de solo da vertente oeste crescendo junto com o capim sapê (Imperata brasiliensis Trin. - Poaceae) em locais bem ensolarados. Conhecida popularmente como quebrapedra, o chá é usado para combater infecções (Barros \& Andrade 1997).

Material examinado: BRASIL. Rio de Janeiro: Niterói, 7///1995, Guerra Santos et al. 63 (RB).

\section{Doryopteris collina (Raddi) J. Sm.}

Hemicriptófita rosulada com distribuição limitada à América do Sul. As folhas pedadas com venação anastomosada e pecíolo castanho, achatado na superfície adaxial e com alas membranosas caracterizam esta espécie na área estudada. Pteridófita terrestre e/ou saxícola encontrada em todo o afloramento rochoso, crescendo junto com Selaginella sellowii e Anemia villosa em ilhas de solo ou na margem das matas. Algumas pteridófitas da Pedra de Itacoatiara apresentam enrolamento foliar para o lado adaxial (D. collina, D. concolor e $D$. varians) ou abaxial (Anemia tomentosa var. anthriscifolia e A. villosa). Dependendo da intensidade do enrolamento, a folha pode não voltar à posição normal, como conseqüência da falta de reidratação. Segundo Larcher (2000), o enrolamento foliar, principalmente em musgos (filídios) e pteridófitas, seria uma estratégia das folhas para receber menor energia solar, minimizando o efeito da radiação excessiva.

Material examinado: BRASIL. Rio de Janeiro: Niterói, 2/I/1994, Guerra Santos et al. 37 (RB); 20/III/1994, Guerra Santos 54 (RB).

\section{Doryopteris concolor (Langsd. \& Fisch.) Kuhn}

Hemicriptófita rosulada de distribuição pantropical. As folhas pedadas com nervuras furcadas e livres distinguem esta espécie na Pedra de Itacoatiara. Apenas uma população foi localizada na área de estudo, crescendo às margens das matas em local úmido. Apresenta enrolamento foliar para o lado adaxial (vide comentários em D. collina).

Material examinado: BRASIL. Rio de Janeiro: Niterói, 2///1994, Guerra Santos et al. 32 (RB).

\section{Doryopteris varians (Raddi) J. Sm.}

Hemicriptófita rosulada de distribuição limitada à América do Sul. Pode ser confundida com D. collina, mas é facilmente distinta desta por possuir pecíolos cilíndricos e negros. Ocorre nas ilhas de solo e nas margens das matas, em locais úmidos. Apresenta enrolamento foliar para o lado adaxial (vide comentários em D. collina).

Material examinado: BRASIL. Rio de Janeiro: Niterói, 2/I/1994, Guerra Santos et al. 33 (RB); 27/VIII/1995, Guerra Santos 386 (RB).

\section{Hemionitis tomentosa (Lam.) Raddi}

Hemicriptófita rosulada de disbribuição limitada à América do Sul. Espécie reconhecida pelas folhas pinadas a bipinadas, pinas pilosas e soros lineares sobre as nervuras. Na área de estudo é encontrada no interior ou nas margens das matas, sendo uma espécie muito freqüente visualmente. O chá é usado como anti-helmíntico e sudorífero (Barros \& Andrade 1997).

Material examinado: BRASIL. Rio de Janeiro: Niterói, 16/IV/1995, Guerra Santos et al. 71 (RB). 
15. Pityrogramma calomelanos (L.) Link var. calomelanos

Hemicriptófita rosulada de distribuição pantropical. Facilmente reconhecida na Pedra de Itacoatiara pela camada de cera alva existente no lado abaxial das folhas. Na área de estudo, esta espécie está representada por poucos indivíduos, que ocorrem crescendo com Pteridium aquilinum var. arachnoideum em clareiras existentes na mata da vertente sudeste. Conhecida pelos nomes populares de feto-branco, avenca-branca ou avenca-preta (Corrêa 1984; Barros \& Andrade 1997) é utilizada como ornamental (Corrêa 1984) e medicinal. É indicada contra distúrbios renais, como adstringente, analgésica, anti-hemorrágica, peitoral, depurativa, emenagoga, antigripal, anti-hipertensiva, antitérmico, antitussígeno e estimulante da circulação sangüínea (May 1978; Barros \& Andrade 1997).

Material examinado: BRASIL. Rio de Janeiro: Niterói, 2///1994, Guerra Santos et al. 35 (RB).

Schizaeaceae

\section{Anemia collina Raddi}

Hemicriptófita rosulada endêmica do Brasil, ocorrendo nos estados de Minas Gerais, Espírito Santo e Rio de Janeiro. Ocorre nas ilhas de solo e pode ser reconhecida pelo par de pinas basais modificadas, pinas de margem inteira a crenada, caule vertical e pilosidade intensa. Apenas uma população foi encontrada na área de estudo. A espécie é utilizada como ornamental (Corrêa 1984).

Material examinado: BRASIL. Rio de Janeiro: Niterói, 20/III/1994, Guerra Santos et al. 49 (RB).

\section{Anemia hirsuta (L.) Sw.}

Geófita rizomatosa de distribuição neotropical. Distinta pelo par de pinas basais modificadas longas, pinas de margem incisa e caule horizontal subterrâneo. Ocorre nas margens da mata do cume da Pedra.

Material examinado: BRASIL. Rio de Janeiro: Niterói, 2/I/1994, M. Guerra Santos et al. 30 (RB).

\section{Anemia tomentosa (Sav.) Sw. var. anthriscifolia} (Schrad.) Mickel

Geófita rizomatosa de distribuição limitada à América do Sul. Na área de estudo é facilmente reconhecida pelo par de pinas basais férteis modificadas e a lâmina bipinada. Pteridófita terrestre encontrada em ilhas de solo da vertente oeste. A. tomentosa var. anthriscifolia é uma planta visualmente freqüente em regiões rochosas do estado do Rio de Janeiro. Apresenta enrolamento foliar na direção abaxial (vide comentários em D. collina). As folhas desta samambaia possuem um aroma característico, que em análise química, revelou ser de um óleo essencial, o isoafricanol (Santos et al. 2003).

Material examinado: BRASIL. Rio de Janeiro: Niterói, 20/III/1994, Guerra Santos et al. 47 (RB); 18/XI/1995, Guerra Santos 611 (RB).

\section{Anemia villosa Humb., Bonpl. ex Willd.}

Hemicriptófita rosulada de distribuição limitada à América do Sul. Os esporângios arranjados em um par de pinas basais modificadas e a lâmina pinadopinatissecta identificam esta espécie na Pedra de Itacoatiara. Pteridófita representada por grandes populações na área de estudo, sendo encontrada nas ilhas de solo, crescendo junto com Selaginella sellowii Hieron. e Doryopteris collina. Apresenta enrolamento foliar na direção abaxial (vide comentários em D. collina). As folhas desta espécie também produzem um óleo essencial, ainda em estudo por pesquisadores do Laboratório de Tecnologia de Produtos Naturais (LTPN) da Universidade Federal Fluminense (UFF).

Material examinado: BRASIL. Rio de Janeiro: Niterói, 2/I/1994, Guerra Santos 29 (RB); 27/VIII/1995, Guerra Santos 387 (RB).

\section{Selaginellaceae}

\section{Selaginella muscosa Spring}

Hemicriptófita reptante de distribuição neotropical. A presença de microfilos e rizóforos ventrais caracterizam esta espécie na Pedra de Itacoatiara, que ocorre como terrestre e/ou saxícola em ambiente úmido.

Material examinado: BRASIL. Rio de Janeiro: Niterói, 7/I/1995, Guerra Santos et al. 65 (RB).

\section{Selaginella sellowii Hieron.}

Hemicriptófita reptante de distribuição neotropical. Na Pedra de Itacoatiara é encontrada nas ilhas de solo ou na margem das matas e reconhecida pelos microfilos uniformes e arranjados espiraladamente. Meirelles et al. (1999), analisando a vegetação de afloramentos rochosos no estado do Rio de Janeiro, afirmam que $S$. sellowii foi a única espécie registrada em ilhas com uma fina camada de solo. Em observações realizadas na área de estudo, constatouse que S. sellowii é visualmente freqüente em toda a Pedra, formando ilhas homogêneas. Nas ilhas maiores 
(com vegetação arborescente e/ou arbórea) ela ocorre nas margens.

Material examinado: BRASIL. Rio de Janeiro: Niterói, 20/III/1994, Guerra Santos et al. 50 (RB).

22. Selaginella sulcata (Desv. ex Poir.) Spring ex Mart.

Hemicriptófita reptante limitada à América do Sul. O caule articulado e os microfilos axilares auriculados caracterizam esta pteridófita terrestre e/ou saxícola que ocorre nas margens das matas.

Material examinado: BRASIL. Rio de Janeiro: Niterói, 20/III/1994, Guerra Santos et al. 48 (RB); 16/IV/1995, Guerra Santos et al. 69 (RB).

Thelypteridaceae

\section{Macrothelypteris torresiana (Gaudich.) Ching}

Hemicriptófita rosulada de distribuição paleotropical. É uma pteridófita do Velho Mundo que foi introduzida nos neotrópicos e rapidamente ampliou sua distribuição geográfica (Mickel \& Beitel 1988; Smith 1992). Na área de estudo pode ser identificada pela lâmina bipinado-pinatissecta e os soros arredondados no lado abaxial. Ocorre em substrato úmido ou com água escorrendo na margem da mata ou entre rochas. Conhecida popularmente como samambaia-da-pedra é utilizada como ritualística em banhos de "descarrego" e medicinal, sendo indicada para dores no corpo, torções, contusões e pancadas (Santos \& Sylvestre 2000).

Material examinado: BRASIL. Rio de Janeiro: Niterói, 2/I/1994, Guerra Santos et al. 36 (RB); Idem, 2/I/1994, Guerra Santos et al. 39 (RB); Idem, 27/VIII/1995, Guerra Santos 384 (RB).

\section{Thelypteris dentata (Forssk.) E.P. St. John}

Hemicriptófita rosulada de distribuição paleotropical. Pteridófita introduzida e subespontânea no Novo Mundo (Smith 1992). Espécie reconhecida na Pedra de Itacoatiara pela lâmina pinado-pinatífida e soros arredondados e indusiados no lado abaxial. Conhecida pelo nome popular de samambaia-do-mato é utilizada como ritualística em banhos de "descarrego" (Santos \& Sylvestre 2000) e ornamental (Côrrea 1984).

Material examinado: BRASIL. Rio de Janeiro: Niterói, 7/I/1995, Guerra Santos et al. 64 (RB).

$\mathrm{Na}$ Pedra de Itacoatiara foram encontradas 24 espécies de pteridófitas, pertencentes a 15 gêneros e nove famílias. A família com maior número de representantes foi Pteridaceae (oito espécies) e os gêneros com maior número de espécies foram Anemia (quatro) e Selaginella (três).

Do número total de espécies inventariadas, 13 possuem usos atribuídos. Destas, 11 são consideradas medicinais (Adiantum raddianum, Adiantopsis radiata, Adiantum serratodentatum, Blechnum serrulatum, Hemionitis tomentosa, Lycopodiella cernua, Microgramma vacciniifolia, Macrothelypteris torresiana, Pteridium aquilinum var. arachnoideum, Pityrogramma calomelanos var. calomelanos e Polypodium triseriale), seis ornamentais (Anemia collina, A. raddianum, A. radiata, $P$. calomelanos var. calomelanos, $P$. triseriale e Thelypteris dentata), três ritualísticas (M. vacciniifolia, M. torresiana e $T$. dentata), uma comestível (P. aquilinum var. arachnoideum) e uma cosmética (M. vacciniifolia). Duas pteridófitas contêm substâncias tóxicas (M. vacciniifolia e P. aquilinum var. arachnoideum).

$\mathrm{Na}$ classificação quanto à forma de vida, as hemicriptófitas rosuladas dominaram $(45,8 \%)$, seguidas de hemicriptófitas reptantes $(29,2 \%)$, geófitas rizomatosas $(20,8 \%)$ e epífitas $(4,2 \%)$. Estes resultados concordam com Meirelles et al. (1999) que registraram $43,5 \%$ de hemicriptófitas para oito afloramentos rochosos do estado do Rio de Janeiro.

A análise da distribuição geográfica dos táxons revelou cinco padrões. A maioria das espécies $(37,5 \%)$ apresenta distribuição neotropical, o que representa nove das 24 espécies inventariadas. Com distribuição limitada à América do Sul foram registradas sete espécies $(29,2 \%)$, quatro espécies $(16,7 \%)$ mostramse pantropicais e duas paleotropicais $(8,3 \%)$. Apenas duas espécies (Anemia collina e Antigramma plantaginea) apresentaram distribuição limitada à região sudeste do Brasil. No estado do Rio de Janeiro, resultados similares foram encontrados para mata atlântica (Sylvestre 1997; Mynssen \& Sylvestre 2001; Mynssen et al. 2002) e restinga (Santos et al. 2004). A ampla distribuição de algumas espécies de pteridófitas pode ser atribuída à maior facilidade de dispersão de seus esporos no ar e por permanecerem viáveis por longas distâncias, aliado a um fenótipo com uma grande amplitude ecológica (Tryon 1970).

Analisando a distribuição das pteridófitas ao longo da Pedra de Itacoatiara, verificou-se que algumas espécies têm ocorrência restrita a uma vertente, enquanto outras são encontradas em praticamente todo o afloramento rochoso, como é o caso de Selaginella sellowii, Doryopteris collina e Microgramma vacciniifolia. Um maior número de espécies é 
encontrado na vertente leste e no topo da Pedra, onde existem formações florestais que contribuem para a maior riqueza pteridofítica. Outro fator é a maior umidade verificada no solo da vertente leste. Sabe-se da necessidade que as pteridófitas têm da água para a reprodução sexuada. Deste modo, elas são preferencialmente encontradas em ambientes ou substratos que possam reter água por, pelo menos, parte do tempo (Windisch 1992), o que não impede o seu crescimento em lugares com restrição hídrica, como é o caso das ilhas de solo dos afloramentos rochosos.

Meirelles et al. (1999) afirmam que as pteridófitas são elementos significativos nas comunidades de ilha de solo nos afloramentos rochosos no Rio de Janeiro. Estes autores alertam para a fragilidade desse ambiente e sua vulnerabilidade a ações antrópicas negativas, como poluição, vandalismo e fogo. Por esse motivo, estudos florísticos e ecológicos em outras regiões rochosas são importantes para caracterizar a pteridoflora que ocupa essas formações tão singulares.

\section{Agradecimentos}

À Loreine Hermida da Silva e Silva, da Universidade Federal do Estado do Rio de Janeiro (UniRio), Professora de Botânica Criptogâmica do primeiro autor, pelo constante incentivo, pela oportunidade de trabalhar em seu laboratório durante a graduação e co-orientação na monografia de bacharelado. Ao amigo e "irmão" Joel Campos de Paula, Biólogo da Universidade do Estado do Rio de Janeiro (UERJ), pelo companheirismo e auxílio técnico durante e depois da graduação. Aos assessores anônimos pelas contribuições ao manuscrito.

\section{Referências bibliográficas}

Alston, A.H.G.; Jermy, A.C. \& Rankin, J.M. 1981. The genus Selaginella in tropical South America. Bulletin of the British Museum (Natural History) Botany 9 (4): 233-330.

Barros, I.C.L. \& Andrade, L.H.C. 1997. Pteridófitas medicinais (samambaias, avencas e plantas afins). Recife, Ed. Universitária da Universidade Federal de Pernambuco.

Brade, A.C. 1965. Contribuição para o conhecimento das espécies brasileiras do gênero Doryopteris (Polypodiaceae). Arquivos do Jardim Botânico do Rio de Janeiro 18: 39-72.

Brade, A.C. 1972. O gênero 'Dryopteris"(Pteridophyta) no Brasil e sua divisão taxonômica. Bradea 1(22): 191-261.

Braga, R. 1976. Plantas do Nordeste, especialmente do Ceará. Mossoró, Escola Superior de Agricultura.
Carauta, J.P.P. \& Oliveira, R.R. 1982. Fitogeografia das encostas do Pão de Açúcar. Pp. 9-31. In: Flora: Alguns estudos - II (Cadernos FEEMA, série trabalhos técnicos 2/82). Rio de Janeiro, Fundação Estadual de Engenharia do Meio Ambiente.

Corrêa, M.P. 1984. Dicionário das plantas úteis do Brasil e das exóticas cultivadas. Rio de Janeiro, Instituto Brasileiro de Desenvolvimento Florestal.

Cruz, G.L. 1965. Livro verde das plantas medicinais e industriais do Brasil. Belo Horizonte.

Harborne, J.B. 1984. Phytochemical methods. A guide to modern techniques of plant analysis. London, Chapman and Hall.

Hensen, R.V. 1990. Revision of the Polypodium loriceumcomplex (Filicales, Polypodiaceae). Nova Hedwigia 50(3-4): 279-336.

Hertwig, I.F.V. 1986. Plantas aromáticas e medicinais. São Paulo, Icone.

Hirai, R.Y. \& Prado, J. 2000. Selaginellaceae Willk. no Estado de São Paulo, Brasil. Revista Brasileira de Botânica 23(3): 313-339.

Hoehne, F.C. 1939. Plantas e substâncias vegetais tóxicas e medicinais. São Paulo, Graphicars.

Kramer, K.U. \& Green, P.S. 1990. Pteridophytes and Gymnosperms. Pp. 1-404. In: K. Kubitzki (ed.). The Families and Genera of Vascular Plants. Berlin, Springer-Verlag.

Larcher, W. 2000. Ecofisiologia vegetal. São Carlos, RiMa.

Lima, C. 1940. Pterideas medicinais indígenas. Tribuna Farmacêutica 8(11): 241-247.

Mas-Guindal, J. 1941. Fitoterapia de los helechos (Pteridofitas helechos). Revista Brasileira de Farmácia 22(7): 395-400.

May, L.W. 1978. The economic uses and associated folklore of ferns and fern allies. The Botanical Review 44(4): 491-528.

Meirelles, S.T.; Pivello, V.R. \& Joly, C.A. 1999. The vegetation of granite rock outcrops in Rio de Janeiro, Brazil, and the need for its protection. Environmental Conservation 26: $10-20$.

Mickel, J.T. 1962. A monographic study of the fern genus Anemia, subgenus Coptophyllum. Iowa State Journal Science 36(4): 349-482.

Mickel, J.T. \& Beitel, J.M. 1988. Pteridophyte Flora of Oaxaca, Mexico. Memoirs of the New York Botanical Garden 46: $1-568$.

Mueller-Dombois, D. \& Ellenberg, H. 1974. Aims and methods of vegetation ecology. New York, John Wiley \& Sons.

Murillo, M.T. 1968. Blechnum subgénero Blechnum en Sur América, com especial referencia a las especies de Colombia. Nova Hedwigia 16: 329-366.

Mynssen, C.M. \& Sylvestre, L.S. 2001. Pteridófitas do Morro Mundo Novo, Rio de Janeiro, RJ. Eugeniana 25: $26-31$.

Mynssen, C.M.; Sylvestre, L.S. \& Andreata, R.H.P. 2002. Pteridófitas das matas de encosta do Jardim Botânico do Rio de Janeiro. Pesquisas (São Leopoldo) 52: 47-87. 
Øllgaard, B. \& Windisch, P.G. 1987. Sinopse das Licopodiáceas do Brasil. Bradea 5(1): 1-43.

Oliveira, R.F.; Filho, A.F.C. \& Silva, Z.L. 1975. Sobre a litosere: algumas espécies para revestimento de encostas rochosas. Brasil Florestal 6(24): 3-18.

Penna, J.F.M. 1946. Dicionário brasileiro de plantas medicinais. São Paulo, Kosmos.

Pichi Sermolli, R.E.G. 1996. Authors of scientific names in Pteridophyta. Kew, Royal Botanic Gardens.

Pontes, J.A.L. 1987. Serra da Tiririca, RJ: necessidade de conservação (Primeira Contribuição). Boletim da Fundação Brasileira para a Conservação da Natureza 22: 89-94.

Porembski, S. 2002. Terrestrial habitat islands as model systems for biodiversity research. Pp. 158-161. In: E.L. Araújo; A.N. Moura; E.V.S.B. Sampaio; L.M.S. Gestinari \& J.M.T. Carneiro (eds.). Biodiversidade, conservaçãoe uso sustentável da Flora do Brasil. Recife, Universidade Federal Rural de Pernambuco.

Porembski, S. \& Barthlott, W. 2000. Granitic and gneissic outcrops (inselbergs) as centers of diversity for desiccation-tolerant vascular plants. Plant Ecology 151: 19-28.

Roriz, A. 1992. Avencas e samambaias. Sítios \& Jardins 8: $1-71$.

Salino, A. \& Semir, J. 2002. Thelypteridaceae (Polypodiophyta) do Estado de São Paulo: Macrothelypteris e Thelypteris subgêneros Cyclosorus e Steiropteris. Lundiana 3: 9-27.

Santos, M.G. \& Sylvestre, L.S. 2000. Pteridófitas comercializadas por erveiros de Niterói e do Rio de Janeiro, RJ, Brasil: uma abordagem etnobotânica. Leandra 15: 79-90.

Santos, M.G.; Sylvestre, L.S. \& Araujo, D.S.D. 2004. Análise florística das pteridófitas do Parque Nacional da Restinga de Jurubatiba, Rio de Janeiro, Brasil. Acta Botanica Brasilica 18(2): 271-280.

Santos, M.G.; Rocha, L.M.; Carvalho, E.S. \& Kelecom, A. 2003. Isoafricanol, um sesquiterpeno incomum encontrado em Anemia tomentosa var. anthriscifolia (Pteridófita). Pp. 58. In: M.O.M. Marques; J.P.F. Teixeira \& S. Scramin (coords.). II Simpósio brasileiro de óleos essenciais: diagnóstico \& perspectivas. Campinas, Documentos Instituto Agronômico de Campinas n. 74.

Santos, M.G; Carvalho, C.E.M.; Kelecom, A.; Ribeiro, M.L.R.C.; Freitas, C.V.C.; Costa, L.M. \& Fernandes, L.V.G. 2005. Cianogênese em esporófitos de pteridófitas avaliada pelo teste do ácido pícrico. Acta Botanica Brasilica 19(4): 783-788.

Santos, R.C.; Brasileiro-Filho, G. \& Hojo, E.S. 1987. Induction of tumors in rats by bracken fern (Pteridium aquilinum) from Ouro Preto (Minas Gerais, Brazil). Brazilian Journal of Medical Biological Research 20: 73-77.

Sehnem, A. 1968. Blecnáceas. Pp. 1-90. In: R. Reitz (ed.). Flora Ilustrada Catarinense. Itajaí, Herbário Barbosa Rodrigues.
Sehnem, A. 1970. Polipodiáceas. Pp. 1-173. In: R. Reitz (ed.). Flora Ilustrada Catarinense. Itajaí, Herbário Barbosa Rodrigues.

Sehnem, A. 1972. Pteridáceas. Pp. 1-244. In: R. Reitz (ed.). Flora Ilustrada Catarinense. Itajaí, Herbário Barbosa Rodrigues.

Sehnem, A. 1974. Esquizeáceas. Pp. 1-78. In: R. Reitz (ed.). Flora Ilustrada Catarinense. Itajaí, Herbário Barbosa Rodrigues.

Sehnem, A. 1979. Aspidiáceas. Pp. 1-356. In: R. Reitz (ed.). Flora Ilustrada Catarinense. Itajaí, Herbário Barbosa Rodrigues.

Silva, A.T. 1984. Pteridófitas. Pp. 33-34. In: O. Fidalgo \& V.L.R. Bononi (coords.). Técnicas de coleta, herborização e preservação de material botânico. São Paulo, Instituto de Botânica.

Smith, A.R. 1992. Pteridophyta of Peru, part III: 16. Thelypteridaceae. Fieldiana, Botany, new series 29: 1-80.

Stellfeld, C. 1951. As drogas da farmacopéia paulista. Tribuna Farmacêutica 19(6): 89-92.

Sylvestre, L.S. 1997. Pteridófitas da Reserva Ecológica de Macaé de Cima. Pp. 41-52. In: H.C. Lima \& R.R. GuedesBruni (eds.). Serra de Macaé de Cima: Diversidade Florística e Conservação em Mata Atlântica. Rio de Janeiro, Instituto de Pesquisas Jardim Botânico do Rio de Janeiro.

Sylvestre, L.S. \& Windisch, P.G. 2002. New combinations in Antigramma C. Presl (Aspleniaceae) and a synopsis of the species. Bradea 8(49): 331-335.

Tryon, R.M. 1941. A revision of the genus Pteridium. Rhodora 43: 1-31, 37-67.

Tryon, R.M. 1942. A revision of the genus Doryopteris. Contributions from the Gray Herbarium of Harvard University 143: 1-80.

Tryon, R.M. 1962. The fern genus Doryopteris in Santa Catarina and Rio Grande do Sul, Brazil. Sellowia 4 : 51-59.

Tryon, R.M. 1970. Development and evolution of fern Floras of oceanic islands. Biotropica 2(2): 76-84.

Tryon, R.M. \& Stolze, R.G. 1989a. Pteridophyta of Peru, part I. 1. Ophioglossaceae - 12. Cyatheaceae. Fieldiana, Botany, new series 20: 1-145.

Tryon, R.M. \& Stolze, R.G. 1989b.Pteridophyta of Peru, part II. 13. Pteridaceae - 15. Dennstaedtiaceae. Fieldiana, Botany, new series 22: 1-128.

Tryon, R.M. \& Stolze, R.G. 1993. Pteridophyta of Peru, part v. 18. Aspleniaceae - 21. Polypodiaceae. Fieldiana, Botany, new series 32: 1-190.

Tryon, R.M. \& Tryon, A.F. 1982. Ferns and allied plants with special reference to Tropical America. New York, Springer-Verlag.

Windisch, P.G. 1992. Pteridófitas da região Norte-ocidental do Estado de São Paulo (Guia para estudo e excursões). São José do Rio Preto, Unesp.

Zurlo, C. \& Brandão, M. 1989. As ervas comestíveis: descrição, ilustração e receitas. Rio de Janeiro, Globo. 